\title{
High Ratio Resuscitation in Patients with Systemic acquired Coagulopathy vs Endogenous Acute Coagulopathy
}

\author{
1Juan Duchesne, ${ }^{2}$ Robert Derenbecker
}

\begin{abstract}
Background: Two main mechanisms of coagulopathy related to trauma have been described: systemic acquired coagulopathy (SAC) and endogenous acute coagulopathy (EAC). Resuscitation with high ratios of fresh frozen plasma to packed red blood cells (FFP:PRBC) has been shown to improve patient outcomes. Systemic acquired coagulopathy is related to acidosis, hypothermia and hemodilution. Endogenous acute coagulopathy is related to severe hemorrhage and shock, with resultant effects on intrinsic clotting pathways inducing coagulopathy more rapidly than SAC. We hypothesize that high ratio resuscitation will show improved mortality outcomes for both SAC and EAC.
\end{abstract}

Study Design: A retrospective chart review was performed for patients at an urban level I trauma center. All patients with international normalized ratio $(\mathrm{INR})>1.2$ during the first 6 hours after admission who received operative intervention and at least 6 units of PRBCs following traumatic injury were included. Patients with INR $>1.2$ on admission were stratified to the EAC group while patients with normal admission INR with subsequent postoperative increase in INR $>1.2$ were stratified into the SAC group. Transfusion ratios for FFP:PRBC were also collected for each patient. High ratio resuscitation was defined as FFP:PRBC $\geq 1: 2$ and low as FFP:PRBC $<1: 2$. Outcomes between groups were analyzed.

Results: Total of 95 patients met inclusion criteria. Fifty-six $(59 \%)$ patients met criteria for EAC and 39 (41\%) patients developed criteria for SAC during the first 6 hours of admission. The initial average base deficit was greater in EAC vs SAC patients $(-6.3 \mathrm{vs}-4.8, \mathrm{p}=0.03)$. Endogenous acute coagulopathy patients had a higher initial INR than SAC (1.4 vs $1.1, p=0.001)$, and a higher average injury severity score (ISS) (27.6 vs 21.5, $p=0.03$ ). Regarding transfusion ratios, for both EAC and SAC, a high transfusion ratio when compared to a low transfusion ratio conveyed improved mortality (EAC: 32.5 vs $81 \%, p=0.01$; SAC: 9 vs $64.7 \%, p=0.03$ ). For high

\footnotetext{
${ }^{1}$ Trauma Medical Director, ${ }^{2}$ Medical Student

${ }^{1}$ Department of Shock Trauma, North Oaks Medical Center Louisiana, USA

${ }^{2}$ Department of Medicine, Louisiana State University Health Sciences Center, Louisiana, USA

Corresponding Author: Juan Duchesne, Trauma Medical Director, Department of Shock Trauma, North Oaks Medical Center, Louisiana, USA, Phone: 9852302477, e-mail: duchesnej@northoaks.org
}

ratio resuscitation in both groups, patients with SAC showed improved mortality compared to EAC ( 9 vs $32.5 \%, p=0.01$ ).

Conclusion: For patients with EAC and SAC, a high transfusion ratio conveyed an overall improvement in mortality. However, subgroup analysis demonstrated that despite a high transfusion ratio, EAC patients continued to have a significantly higher mortality than SAC patients. Further investigations into the mechanisms involved in EAC and interventions to improve outcomes are needed.

Keywords: Coagulopathy, Hemorrhage, Resuscitation.

How to cite this article: Duchesne J, Derenbecker R. High Ratio Resuscitation in Patients with Systemic acquired Coagulopathy vs Endogenous Acute Coagulopathy. Panam J Trauma Crit Care Emerg Surg 2014;3(2):68-72.

Source of support: Nil

Conflict of interest: None

\section{ABSTRACTO}

Fondo: Se han descrito dos mecanismos principales de coagulopatía relacionadas con trauma: sistémica adquirida coagulopatía (SAC) y coagulopatía aguda endógena (EAC). Resucitación con altos coeficientes de plasma fresco congelado a glóbulos rojos empaquetados (FFP:PRBC) se ha demostrado para mejorar los resultados del paciente. Coagulopatía sistémica adquirida está relacionada con la acidosis, hipotermia y hemodilución. Coagulopatía aguda endógeno está relacionada con la hemorragia severa y shock, con efectos resultantes sobre vías de coagulación intrínsecas induciendo coagulopatía más rápidamente que el SAC. Presumimos que reanimación alto cociente mostrará los resultados de mortalidad mejoradas para SAC y EAC.

Diseño del estudio: Una revisión retrospectiva fue realizada para los pacientes en un urbano centro de trauma de nivel I. Se incluyeron todos los pacientes con razón internacional normalizada (INR) 1.2 durante las primeras 6 horas después de la admisión que recibieron la intervención operativa y por lo menos 6 unidades de sangre después de una lesión traumática. Los pacientes con INR > 1.2 en la admisión se estratificaron a el grupo EAC mientras que pacientes con admisión normal INR con aumento subsecuente postoperatoria en INR > 1.2 se estratificaron en el grupo SAC. También fueron las proporciones de transfusión para FFP:PRBC recogidos para cada paciente. Se definió la resucitación alto cociente como FFP:PRBC $\geq 1: 2$ y baja como FFP:PRBC $<1: 2$. Resultados entre los grupos fueron analizados.

Resultados: Total de 95 pacientes con criterios de inclusión. Cincuenta y seis los pacientes (59\%) cumplieron 
criterios para EAC y 39 pacientes (41\%) desarrollado criterios para SAC durante las primeras 6 horas de admisión. El déficit de base promedio inicial fue mayor en EAC los pacientes vs SAC (-6.3 vs $-4.8, p=0,03)$. Endógenos aguda coagulopatía pacientes tenían un INR inicial más alto que SAC $(1.4$ vs $1.1, p=0.001$ ) y una mayor puntuación de gravedad promedio lesions (ISS) $(27,6$ vs $21,5, p=0,03)$. En cuanto a las proporciones de la transfusión, para EAC tanto SAC, una proporción alta de transfusión en comparación a una transfusión de baja relación transmitió mayor mortalidad (EAC: 32,5 vs $81 \%, p=0,01$; SAC: 9 vs 64,7\%, $p=0,03$ ). Para la resucitación de alto cociente demonstro en ambos grupos, los pacientes con SAC mejora la mortalidad en comparación con EAC ( 9 vs $32,5 \%, p=0,01)$.

Conclusión: en pacientes con EAC y SAC, una transfusión de alta cociente transmitió una mejora general en la mortalidad. Sin embargo, Análisis de subgrupos demostraron que a pesar de una transfusión de alta proporción de pacientes EAC continuados teniendo una significativamente mayor, mortalidad de los pacientes SAC. Fomente las investigaciones sobre el mecanismos implicados en la EAC y las intervenciones para mejorar los resultados son necesarios.

Palabras claves: Coagulopatía, Hemorragia, Resucitación.

\section{INTRODUCTION}

It has been demonstrated that up to $40 \%$ of trauma mortalities are due to severe hemorrhage. ${ }^{1}$ Hemostasis following trauma can be complicated by coagulopathy, which poses a common and life-threatening challenge to the management of severe hemorrhage. ${ }^{2}$ The ability to control and understand the principles of coagulopathy after severe hemorrhage is of utmost importance. Recent research has indicated at least two separate coagulation abnormalities affecting trauma patients: endogenous acute coagulopathy (EAC) and systemic acquired coagulopathy (SAC). ${ }^{3}$ Regardless of the coagulopathy mechanism, hemostatic resuscitation has become the mainstay of treatment of acute hemorrhage.

As the understanding of coagulopathy associated with trauma has grown, it is proposed that at least two distinct mechanisms are involved. ${ }^{3-6}$ These mechanisms are clearly classified by Cohen and West: (1) SAC and (2) EAC. ${ }^{4}$ Systemic acquired coagulation describes the coagulopathy classically associated with trauma patients caused by acidosis, hemodilution and hypothermia. These patients are not coagulopathic on arrival to the trauma center. Rather, this coagulopathy develops during the resuscitation phase from consumption of coagulation factors due to ongoing hemorrhage. Additionally, dilution and hypothermia, which may be caused iatrogenically by use of traditional resuscitation protocols, contribute to SAC. Endogenous acute coagulopathy describes a coagulopathy present upon arrival to the trauma center. Hypoperfusion and shock play a large role in the mechanism of EAC. Other mechanisms postulated for EAC are poorly understood but likely involve a combination of several endogenous coagulation abnormalities. A better understanding of EAC may allow optimization of therapeutic resuscitation.

Many investigations of optimal resuscitation methods have been performed as massive transfusion protocols (MTPs) are developed for the treatment of acute hemorrhage. Recent studies have concluded that a close ratio of 1:1 fresh frozen plasma (FFP) to packed red blood cells (PRBCs) results in better outcomes. ${ }^{7,8}$ Further investigation is warranted to analyze patients with both SAC and EAC, who are treated with hemostatic resuscitation. It is postulated that these two mechanisms warrant a separate targeted approach at resuscitation. ${ }^{4}$ We hypothesize that high ratio resuscitation will show improved mortality outcomes for both SAC and EAC.

\section{METHODS OF RESEARCH}

A retrospective chart review was performed over 39 months (August 2005-November 2008) from the Medical Center of Louisiana Spirit of Charity Level I Trauma Center approved by the Louisiana State University Health Sciences Center Institutional Review Board. Inclusion criteria for trauma patients: $\geq 18$ years old, underwent emergency surgery, and received 6 or more units of packed red blood cells intraoperatively, with an international normalized ratio (INR) $>1.2$ within 6 hours of admission.

Patients were stratified into two separate groups: EAC and SAC. Endogenous acute coagulopathy was defined as an INR $\geq 1.2$ upon arrival to the emergency department. Systemic acquired coagulopathy was defined as an INR $\geq 1.2$ postoperatively within 6 hours of admission in a patient who presented to the emergency department with a normal INR. The MTP was changed in 2007 to a goal of a matched 1:1 ratio of FFP:PRBC, however, this goal was not perfectly obtained in hemostatic resuscitation for all patients. Previously, the MTP reflected a transfusion ratio

Table 1: Patient demographics for EAC and SAC groups

\begin{tabular}{llll}
\hline & $\begin{array}{l}\text { EAC } \\
(n=56)\end{array}$ & $\begin{array}{l}\text { SAC } \\
(n=39)\end{array}$ & $p$ \\
\hline Age (years) & 29 & 31 & 0.19 \\
Male (\%) & 85 & 90 & 0.59 \\
Penetrating injury (\%) & 65 & 75 & 0.86 \\
Arrival base deficit & 6.3 & 4.8 & 0.03 \\
Arrival INR & 1.4 & 1.1 & 0.001 \\
Arrival hemoglobin (gm/dl) & 9.2 & 8.4 & 0.96 \\
ISS & 27.6 & 21.5 & 0.03 \\
TICU length & 12.6 & 15.6 & 0.55 \\
of stay (days) & & & \\
30-day mortality (\%) & 46 & 33 & 0.33 \\
\hline
\end{tabular}

EAC: Endogenous acute coagulopathy; SAC: Systemic acquired coagulopathy; INR: International normalized ratio; ISS: Injury severity score; TICU: Trauma intensive care unit 


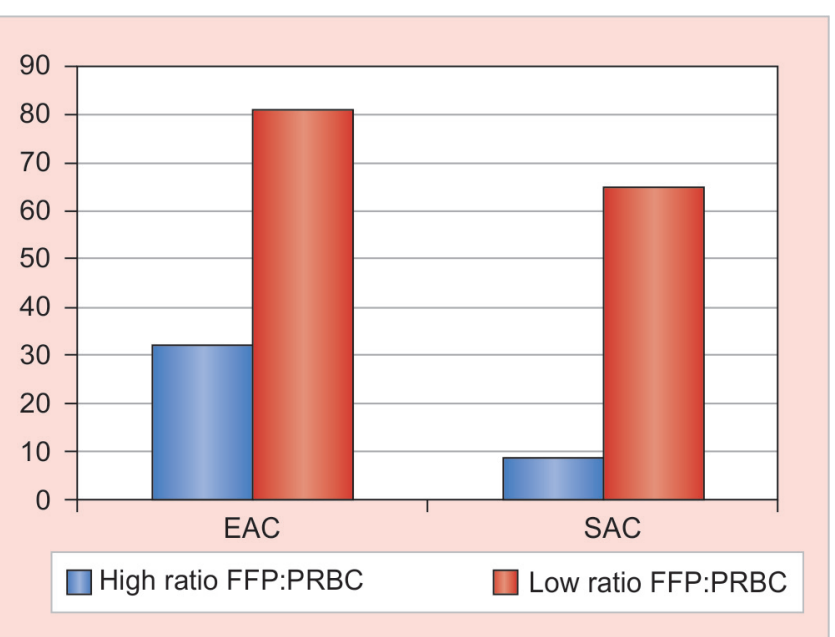

Graph 1: 30-day mortality in EAC and SAC with high ratio and low ratio FFP:PRBC

of 1:6 FFP:PRBC. With this change in mind, EAC and SAC groups were subdivided into two groups according to the hemostatic resuscitation ratios, they received in the emergency department and intraoperatively: high (FFP:PRBC $\geq 1: 2$ ) and low (FFP:PRBC $<1: 2$ ).

Demographics compared between the groups included: gender, age (years), mechanism of injury (penetrating vs blunt), hemoglobin $(\mathrm{gm} / \mathrm{dl}), \mathrm{INR}$, base deficit $(\mathrm{mEq} / \mathrm{l})$ and injury severity score (ISS). Intensive care unit (ICU) length of stay (LOS, days) and 30-day mortality were also recorded.

Data were analyzed using Statistical Analysis Software (SAS) version 9.1.3 (Cary, NC). A linear regression model was used to compare mean ICU LOS and 30-day mortality between EAC and SAC groups. We further compared mortality between EAC and SAC groups by high transfusion ratio and low transfusion ratio subsets.

\section{RESULTS}

Throughout the study period, 95 patients met inclusion criteria. Fifty-six (59\%) patients met criteria for EAC and 39 (41\%) patients developed criteria for SAC during the first 6 hours of admission. The mean age for patients with EAC $v s$ SAC was $29 v s 31$ years old $(\mathrm{p}=0.19)$. Males made up $85 \%$ of the EAC group and $90 \%$ of the SAC group ( $\mathrm{n}=48$ and 35 respectively). Number of penetrating injuries in EAC vs

Table 2: Mortality outcomes of low and high ratio FFP:PRBC intraoperative resuscitation in EAC and SAC patients

\begin{tabular}{llll}
\hline Mortality & Low ratio & High ratio & $p$ \\
& FFP:PRBC $<1: 2$ & FFP:PRBC $>1: 2$ & \\
\hline EAC $(\mathrm{n})$ & $13 / 16$ & $13 / 40$ & 0.01 \\
$\%$ & 81 & 32.5 & \\
SAC $(\mathrm{n})$ & $11 / 17$ & $2 / 22$ & 0.03 \\
$\%$ & 65 & 9 & \\
\hline
\end{tabular}

FFP: Fresh-frozen plasma; PRBC: Packed red blood cell; EAC: Endogenous acute coagulopathy; SAC: Systemic acquired coagulopathy
SAC patients consisted of $34(65 \%)$ vs $26(75 \%, \mathrm{p}=0.86)$. Average initial hemoglobin in EAC vs SAC patients was $9.2 \mathrm{gm} / \mathrm{dl} v s 8.4 \mathrm{gm} / \mathrm{dl}(\mathrm{p}=0.96)$. The initial average base deficit in EAC vs SAC patients was $6.3 \mathrm{mEq} / 1$ vs $4.8 \mathrm{mEq} / 1$ $(\mathrm{p}=0.03)$. Initial average INR of EAC $v s \mathrm{SAC}$ was $1.4 v s$ $1.1(\mathrm{p}=0.001)$. The average ISS for EAC $v s$ SAC patients was $27.6 v s 21.5(\mathrm{p}=0.03)($ Table 1$)$.

Using a linear regression model, the ICU LOS between the EAC and SAC groups was shown to be equivalent. Endogenous acute coagulopathy patients stayed on average 12.6 days while SAC stayed 15.6 days $(\mathrm{p}=0.55)$. Although, it did not reach statistical significance, there was a trend toward an increased mean 30-day mortality among EAC vs SAC patients, 46 vs 33\% $(\mathrm{n}=30$ and 26 respectively; $\mathrm{p}=0.33$ ).

Within the EAC group, there was a statistically significant decrease in mortality between high $v s$ low transfusion ratios, $32.5 \%(\mathrm{n}=13)$ vs $81 \%(\mathrm{n}=13) ; \mathrm{p}=0.01$. Similarly, a decrease in mortality was demonstrated in the SAC group, with high $v s$ low ratio groups $9 \%(\mathrm{n}=2) v s 65 \%(\mathrm{n}=11)$; $\mathrm{p}=0.03$. Within patients receiving high ratio resuscitation, mortality rate among EAC vs SAC patients remains significantly higher, $32.5 \%(\mathrm{n}=13)$ vs $9 \%(\mathrm{n}=2) ; \mathrm{p}=0.01$ (Table 2, Graph 1).

\section{DISCUSSION}

The results of this study add supporting evidence to the previously proposed mechanisms of EAC and SAC. Our results demonstrated that EAC patients arrive to the trauma center already coagulopathic, while SAC patients develop a coagulopathy postoperatively within 6 hours of admission. Prior papers have hypothesized that the coagulopathy of EAC is directly related to shock and hypoperfusion; ${ }^{4,9}$ SAC is associated with factors that are frequently iatrogenically imposed during acute resuscitation, such as the development of acidosis, hemodilution and hypothermia. ${ }^{4,9}$ Under certain circumstances, SAC may further complicate the coagulopathy of EAC. ${ }^{4,9}$ Our study further elucidates the difference in character between SAC and EAC adds evidence to support the mechanisms of these two entities. Flowchart 1 illustrates a possible schematic of the mechanisms involved in both SAC and EAC.

Our study demonstrates the interplay of the three factors of injury; namely, ISS, initial INR and initial base deficit. On admission, we observed a significant difference in the ISS between EAC and SAC groups (27.6 vs 21.5). Previously demonstrated coagulopathies are appreciated in more severely injured patients, ${ }^{3,10}$ which is supported here by differences in average initial INR between EAC and SAC groups (1.4 vs 1.1). Additionally, the average base deficit was greater for EAC patients. This difference reflects 




Flowchart 1: Schematic of proposed events leading to the development of EAC and SAC

the degree of blood loss, with resulting hypoperfusion and acidosis. Brohi et al showed similar results concluding that no patients with a normal base deficit had prolonged clotting times, and patients with a base deficit greater than $6 \mathrm{mEq} / 1$ were more likely to have prolonged clotting times. ${ }^{9}$ There was a significant difference among the factors of ISS, initial INR, and initial base deficit suggesting that these differences combined induce a greater degree of coagulopathy in patients with EAC vs SAC.

We have been able to identify EAC and SAC as two entities based on differences in ISS initial INR, and initial base deficit. However, there is clearly further investigation needed to elucidate the pathologic mechanisms linking these clinical findings to the disease processes associated with traumatic coagulopathy. ${ }^{4}$ Other authors have previously hypothesized mechanisms for the different types of coagulopathy following trauma. This study explored the principles of coagulopathy associated with trauma previously hypothesized by Cohen and West. ${ }^{4}$ They propose multiple mechanistic involvements in the coagulopathies of trauma and emphasize that multiple factors are at play in EAC. Tissue hypoperfusion secondary to severe hemorrhage induces an anticoagulant function through thrombomodulin and protein C. ${ }^{9}$ Furthermore, tissue plasminogen activator induces hyperfibrinolysis adding to the coagulopathy associated with trauma. Many agree that further investigation is needed to better describe the multiple pathways associated with severe tissue injury to optimally address these coagulopathies through hemostatic resuscitation strategies. ${ }^{11}$

The degree of coagulopathy correlates with injury severity and will progress if no successful intervention is performed. ${ }^{10-12}$ Multiple studies have shown that a near
1:1 ratio of FFP:PRBC provides the best damage control resuscitation. ${ }^{7,13,14}$ Our study supports the importance of proper hemostatic resuscitation following traumatic injury to counteract this coagulopathy. While both study groups benefited with high ratio resuscitation, SAC patients had better mortality outcomes when compared to EAC. This survival benefit is likely related to the different pathologic mechanisms involved in each type of coagulopathy. While EAC involves endogenous physiologic processes, SAC may be considered related to iatrogenic factors and shortcomings of the resuscitation process. ${ }^{4,6}$ Traditionally, SAC is understood to be caused by a dilution of clotting factors and the loss of blood products through hemorrhage. By using component therapy to replace what the patient is losing through hemorrhage, it is reasonable to expect that coagulopathy associated with trauma should be corrected through high ratio blood product resuscitation.

High ratio resuscitation is important for any patient with coagulation abnormalities following trauma, either SAC or EAC. While prior studies have demonstrated the importance of high ratio resuscitation, ${ }^{7,13,14}$ no study has examined the effect of high ratio resuscitation in relation to the two types of coagulopathy associated with trauma. Our study is unique in that it demonstrates a comparison between the two pathologic entities, SAC and EAC. As previously suggested, EAC contributes to excessive hemorrhage and many of these patients will also subsequently manifest SAC if not properly resuscitated. ${ }^{4}$ This hypothesis was supported here as mortality was higher in patients initially presenting with EAC when low ratio resuscitation was used $(81 \%)$ when compared to the EAC patients appropriately resuscitated with high ratio resuscitation (32.5\%). 
The correct and rapid identification of EAC vs SAC poses a challenge to future treatment efforts. Currently, the main distinguishing factor between EAC and SAC is the patient's INR on arrival to the emergency department. ${ }^{4,15}$ However, our current methods of evaluating coagulopathy are not rapid enough to provide information in a time frame that would be able to influence treatment. Newer methods for point-of-care testing, such as bedside prothrombin time or thromboelastometry, may prove useful in this effort. ${ }^{11,16}$ Faster diagnostic methods will be important for the identification of early coagulopathy, as seen in EAC. These methods would also allow for the future implementation of specialized treatments.

While much remains to be learned about the coagulopathy associated with trauma, it is known that the degree of coagulopathy correlates with injury severity and will progress if no successful intervention is performed. ${ }^{10,12}$ Interventions to halt and reverse the coagulopathy of trauma are vital to reduce mortality and improve outcomes following traumatic injury. ${ }^{17-19}$ Therefore, further investigations are needed to more accurately characterize the coagulopathies associated with trauma to determine appropriate hemostatic resuscitation.

\section{CONCLUSION}

Our study provides a further understanding of at least two different forms of acute traumatic coagulopathy: SAC and EAC. For patients with EAC and SAC, a high transfusion ratio $v s$ low transfusion ratio conveyed an overall improvement in mortality. However, subgroup analysis demonstrated that despite a high transfusion ratio, EAC patients continued to have a significantly higher mortality than SAC patients. Further investigations into the mechanisms involved in EAC and interventions to improve outcomes are needed.

\section{REFERENCES}

1. Sauaia A, Moore FA, Moore EE, Moser KS, Brennan R, Read RA, et al. Epidemiology of trauma deaths: a reassessment. J Trauma 1995;38(2):185-193.

2. Hoyt D, Dutton R, Hauser C, Hess J, Holcomb J, Kluger Y, et al. Management of coagulopathy in the patients with multiple injuries: results from an international survey of clinical practice. J Trauma 2008;65(4):755-765.

3. Brohi K, Singh J, Heron M, Coats T. Acute traumatic coagulopathy. J Trauma 2003;54(6):1127-1130.
4. Cohen M, West M. Acute traumatic coagulopathy: from endogenous acute coagulopathy to systemic acquired coagulopathy and back. J Trauma 2011;70(5):S47-S49.

5. Murthi S, Stansbury L, Hess J. Blood and coagulation support in trauma. Blood Reviews 2009;23:149-155.

6. Hess J, Brohi K, Dutton R, Hauser CJ, Holcomb JB, Kluger Y, et al. The coagulopathy of trauma: a review of mechanisms. J Trauma 2008;65(4):748-754.

7. Duchesne JC, Hunt JP, Wahl G, Marr AB, Wang YZ, Weintraub $\mathrm{SE}$, et al. Review of current blood transfusions strategies in a mature level I trauma center: were we wrong for the last 60 years? J Trauma 2007;65(2):272-278.

8. Duchesne J, Islam T, Stuke L, et al. Hemostatic resuscitation during surgery improves survival in patients with traumaticinduced coagulopathy. J Trauma 2009;67:33-39.

9. Brohi K, Cohen M, Davenport R. Acute coagulopathy of trauma: mechanism, identification and effect. Curr Opin Crit Care 2007; 13:680-685.

10. Maegele M, Lefering R, Yucel N, Tjardes T, Rixen D, Paffrath T, et al. Early coagulopathy in multiple injury: an analysis from the German Trauma Registry on 8724 patients. Injury 2007;38(3): 298-304.

11. Davenport R, Manson J, De'Ath H, Platton S, Coates A, Allard $\mathrm{S}$, et al. Functional definition and characterization of acute traumatic coagulopathy. Crit Care Med 2011;39(12):1-7.

12. MacLeod JB, Lynn M, McKenny MG, Cohn SM, Murtha M. Early coagulopathy predicts mortality in trauma. J Trauma 2003; 55(1):39-44.

13. Borgman MA, Spinella PC, Perkins JG, Grathwohl KW, Repine T, Beekley AC, et al. The ratio of blood products transfused affects mortality in patients receiving massive transfusions at a combat support hospital. J Trauma 2007;63(4):805-813.

14. Duchesne JC, Barbeau JM, Islam TM, Wahl G, Greiffenstein P, McSwain NE. Damage control resuscitation: from emergency department to the operating room. Am Surg 2011;77:201-206.

15. Schreiber MA, Perkins J, Kiraly L, Underwood S, Wade C, Holcomb JB. Early predictors of massive transfusion in combat casualties. J Am Coll Surg 2007;205(4):541-545.

16. Schöchl H, Nienaber U, Hofer G, Voelckel W, Jambor C, Scharbert G. Goal-directed coagulation management of major trauma patients using thromboelastometry $\left(\right.$ ROTEM $\left.^{\circledR}\right)$-guided administration of fibrinogen concentrate and prothrombin complex. Crit Care 2010;14(R55):1-11.

17. Lier H, Böttiger B, Hinkelbein J, Krep H, Bernard M. Coagulation management in multiple trauma: a systemic review. Intensive Care Med 2011;37:572-582.

18. Johansson PI, Stensballe J. Effect of haemostatic control resuscitation on mortality in massively bleeding patients: a before and after study. Vox Sanguinis 2009;96:111-118.

19. Cotton BA, Gunter OL, Isbell J, Au BK, Robertson AM, Morris JA, et al. Damage control hematology: the impact of a trauma exsanguination protocol on survival and blood product utilization. J Trauma 2008;64(5):1177-1183. 